\title{
O SCRATCH COMO AUXILIAR NO PROCESSO DE ENSINO- APRENDIZAGEM DE LINGUAGEM DE PROGRAMAÇÃO: UM BALANÇO DA PÓS-GRADUAÇÃO NACIONAL ENTRE 2010 E 2016
}

\author{
El SCRATCH COMO AUXILIAR EN EL PROCESO DE ENSEÑANZA- \\ APRENDIZAJE DE LENGUAJE DE PROGRAMACIÓN: UN BALANCE DE LA \\ POSTGRADUACIÓN BRASILEÑA ENTRE 2010 Y 2016
}

\author{
SCRATCH AS AUXILIARY TOOL IN THE PROGRAMMING LANGUAGE \\ TEACHING-LEARNING PROCESS: A BRAZILIAN POST-GRADUATION \\ BALANCE BETWEEN 2010 AND 2016
}

\author{
Ivan Rodrigues de CAMARGO ${ }^{1}$ \\ Ivan FORTUNATO ${ }^{2}$
}

RESUMO: Esse trabalho visa fazer um levantamento do tipo estado da arte do programa Scratch aplicado ao processo de ensino-aprendizagem de linguagem de programação. Para isso foram realizadas pesquisas no repositório de teses e dissertações da CAPES, com a intenção de filtrar os trabalhos com conteúdo mais pertinente à proposta. Os dados encontrados demonstram que o uso da ferramenta teve um aumento gradativo ao longo do tempo, começando com poucos materiais em 2010, quando a ferramenta estava nos seus anos iniciais, e foi crescendo conforme os anos foram passando, tendo em vista a grande quantidade de materiais encontrados sobre o assunto no ano de 2016. Esse interesse crescente em se pesquisar o Scratch como ferramenta de apoio e objeto de aprendizagem demonstra que a ferramenta tem atendido ao seu propósito de facilitar o ensino e a apropriação da linguagem de programação.

PALAVRAS-CHAVE: Ensino de linguagem de programação. Objeto de aprendizagem. Scratch.

RESUMEN: Este trabajo pretende hacer un levantamiento del tipo estado del arte del programa Scratch aplicado al proceso de enseñanza-aprendizaje de lenguaje de programación. Por tanto se realizaron investigaciones en el repositorio de tesis y disertaciones de la CAPES (Brasil), con la intención de filtrar los trabajos con contenido más pertinente a la propuesta. Los datos encontrados demuestran que el uso de la herramienta tuvo un aumento gradual a lo largo del tiempo, empezando con pocos materiales en 2010, cuando la herramienta estaba en sus años iniciales, y fue creciendo conforme los años pasaron, teniendo en vista la gran cantidad de los materiales encontrados sobre el tema en el año 2016. Este interés creciente en buscar el Scratch como herramienta de apoyo y objeto de aprendizaje demuestra que la herramienta ha

\footnotetext{
${ }^{1}$ Instituto Federal de São Paulo (IFSP) Itapetininga - SP - Brasil. Especialista em Informática Aplicada à Educação. E-mail: Ivan.camargo2@fatec.sp.gov.br

2 Instituto Federal de São Paulo (IFSP) Itapetininga - SP - Brasil. Coordenadoria de Formação Pedagógica \& Universidade Federal de São Carlos (UFSCar) Sorocaba - SP - Brasil. Programa de PósGraduação em Educação. ORCID: <https://orcid.org/0000-0002-1870-7528>. E-mail: ivanfrt@yahoo.com.br
} 
atendido a su propósito de facilitar la enseñanza y la apropiación del lenguaje de programación.

PALABRAS CLAVE: Enseñanza de lenguaje de programación. Objeto de aprendizaje. Scratch.

ABSTRACT: This paper was developed as a state-of-the-art survey of the Scratch program applied to the teaching-learning process of programming language. For this purpose, a research was carried out in the Brazilian theses and dissertations data-base. The data show that tool use has gradually increased over time, starting with few researches done by 2010, when the tool was in its initial years, and has been growing as the years went by, given the large amount of materials found on the subject in the year 2016. This growing interest in researching the Scratch as a support tool and learning object demonstrates that it has served its purpose of facilitating both teaching and learning of the programming language.

KEYWORDS: Programming language teaching. Learning object. Scratch.

\section{Introdução}

O presente trabalho é resultado de uma pesquisa de pós-graduação lato sensu em informática aplicada à educação, desenvolvida no Instituto Federal de São Paulo, campus Itapetininga. O objetivo principal foi realizar uma pesquisa de revisão bibliográfica, fazendo uma análise do banco de teses da CAPES, buscando mapear a produção de Dissertações e Teses que abordem a utilização da ferramenta Scratch como instrumento auxiliador no processo de ensino-aprendizagem de linguagem de programação.

As motivações que levaram ao desenvolvimento deste trabalho de conclusão de curso partiram da observação da dificuldade generalizada, identificada por meio de experiência direta como aluno e professor de linguagem de programação, desde o ano de 2010, atuando do $2^{\circ}$ ao $9^{\circ}$ ano do Ensino Fundamental. Pretendeu-se, assim, fazer o levantamento das pesquisas mais recentes sobre o assunto, com a intenção de corroborar a ideia de que o uso de ferramentas como o Scratch é uma maneira eficaz de contextualizar e ensinar aspectos elementares da prática de linguagem de programação.

Para alcançar o objetivo proposto, o trabalho foi dividido nas seguintes seções: (1) apresentação geral da interface do Scratch, (2) o levantamento realizado no repositório da Capes, qualificando as teses e dissertações selecionadas, e (3) a análise qualitativa do material encontrado. Ao final, espera-se que o presente estudo de revisão 
ajude a compreender melhor o Scratch como uma potencial ferramenta de ensino de linguagem de programação para estudantes do ensino fundamental.

\section{A interface geral do Scratch}

O Scratch é um software de linguagem gráfica de programação destinado ao desenvolvimento de jogos. Foi criado de 2008, no Media Lab, do Instituto de Tecnologia de Massachusetts (MIT), inspirando-se em plataformas de desenvolvimento mais antigas, que já tinham o intuito de tornar o ensino de programação algo mais acessível. Sua principal inspiração foi a linguagem LOGO, criada no MIT no final da década de 1960. Um dos trabalhos mais emblemáticos e conhecidos que o utilizou essa linguagem, e ainda é usada como referência em cursos de robótica, é a tartaruga programada para seguir determinado comando de movimento como, por exemplo, dar dois (02) passos para frente, parar e virar à direita. Essa tartaruga passou a ser o símbolo dessa linguagem.

De acordo com Martins (2012), a inspiração para a linguagem LOGO partiu de análises feitas a partir da teoria psicogenética de Jean Piaget, e foi elaborada por um grupo de pesquisadores entre os anos de 1960 e 1970. Sua ideia inicial era possibilitar que uma criança pudesse comandar um robô, ou uma abstração de um robô na tela de um computador. Apesar da aparente facilidade de trabalho com os robôs ou tartarugas, o Scracth é ainda mais acessível, sendo uma ferramenta fácil de utilizar e mais intuitiva. Ela foi apresentada e lançada oficialmente no mundo em 15 de maio de 2007, tornandose, de imediato, um objeto de aprendizagem altamente popular e bem-sucedido. Isso porque é muito simples se criar jogos, animações, histórias interativas, arte e outros, o que aumenta a interatividade entre o aluno e a linguagem.

O termo Scratch deriva-se da técnica de Scratching, utilizada pelos DiscoJockeys do HipHop, que manipulam, por exemplo, um discos de vinil com as suas mãos para frente e para trás fazendo infinitas misturas e distorções musicais de forma criativa e inesperada. Com o Scratch, é possível fazer algo bem parecido, no caso, combinando diferentes tipos de mídia (gráficos, fotos, músicas, sons) de forma criativa (FILHO, 2016). O programa é traduzido para cerca de 40 idiomas, sendo acessado em mais de 150 países. O Scratch pode ser programado online, no próprio site, ou pode também ser baixado, o que provê uma melhor comodidade, já que o programa é incrivelmente leve, apesar de possibilitar a criação de jogos robustos. 
Segundo Rodeghiro (2016), o Scratch pode ajudar jovens, adultos e idosos a pensar de forma mais criativa e mais atenta. Ainda, o Scratch foi pensado para estimular o chamado pensamento computacional, termo elaborado para definir as dimensões alcançadas pelas tecnologias da informação e comunicação, onde já se acredita em uma forma de se trabalhar a possibilidade de estimular competências que facilitam a interação, produção e manipulação em dispositivos digitais. Trata-se de um software gratuito que possui um ambiente de desenvolvimento no qual não é preciso digitar funções, endereços, estruturas de repetição, estruturas de decisão, bastando escolher blocos que se encaixam quase como em um jogo de quebra-cabeça, formando uma sequência de comandos desejada. Dessa forma, no Scratch, os blocos se encaixam de maneira única, ligando comandos que se complementam apenas de uma única forma, evitando, assim, erros de sintaxe (LUMMERTZ, 2016). Seu objetivo primário é facilitar a introdução de conceitos de matemática e de computação, bem como o pensamento criativo, o raciocínio sistemático.

Na versão $2.0^{3}$, os blocos de grupos de comandos para construção das operações do objeto (movimento, aparência, som, caneta, controle, sensores, números e variáveis) estão no centro. A região central da tela é o local onde a programação do jogo é elaborada. As estruturas em blocos de comando são conectadas como se fossem peças do famoso jogo estrutural Lego® (RODRIGUES, 2015). A parte que corresponde à animação em si, à esquerda, é chamada de Palco, e a área à direita é chamada de Construção. Nesta área, os blocos são encaixados, tal como um jogo de quebra-cabeça, para formar o algoritmo (sequência de passos lógicos, para executar uma ação) para que a animação ocorra (figura 01).

Figura 01: Tela do Scratch

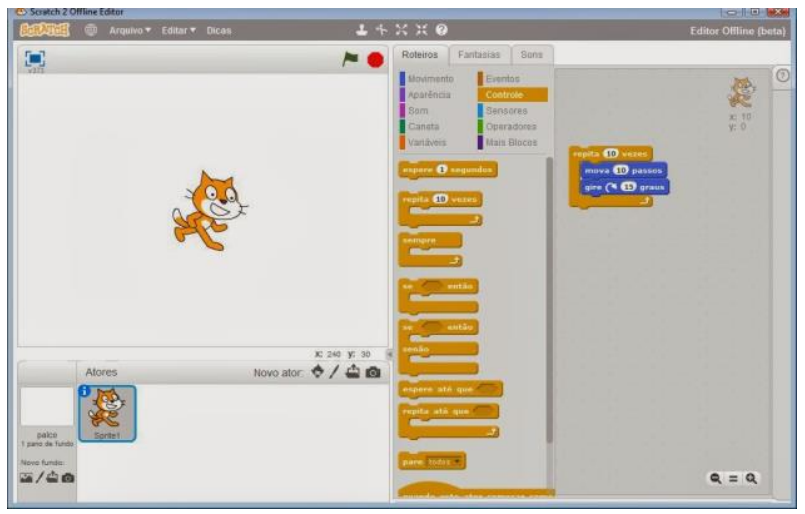

Fonte: Scrath - Adaptado pelos autores

${ }^{3} 2.0$ é a versão mais recente até o momento de produção deste artigo, em novembro de 2017. 
Tomando como base a figura 01, é possível observar, na área construção, o seguinte comando sendo ordenado: Mova 10 passos e gire 15 graus à direita por 10 vezes. Como, nesse caso, não foi estipulada a direção do movimento, o personagem irá movimentar-se, por padrão, à direita, ou seja, no eixo positivo de x (RODRIGUES, 2015). E assim vão sendo construídos, em cada grupo de blocos, uma sequência lógica que dará vida a toda uma animação, sendo possível a criação de jogos das mais variadas formas, tais como quizzes, jogos em modelo plataforma, desafios, storyboards etc., tudo de forma visual, facilitando a elaboração de qualquer tipo de projeto dessa natureza.

Ainda na tela inicial do software, existem diversos grupos de comando, como, por exemplo: aparência, som, caneta, controle, sensores, números e movimento. A "aparência" é utilizada, entre outras coisas, para substituição das vestimentas, que chamamos de trajes (imagem gráfica do objeto), útil como técnica de efeito para simulação de movimentos, como em desenhos animados (RODEGHIRO, 2016). Por exemplo: em um movimento que se faz à direita, muda-se de fantasia a cada 0.1 segundos, dando a impressão de animação da imagem inserida no palco.

Os comandos de "som" proveem a possibilidade de inserir músicas para as atividades que forem desenvolvidas. A aba chamada "caneta" desenha traços deixados quando o objeto é movimentado, alterando cor, espessura e tonalidade. O bloco denominado "controle" possui comandos pré-definidos, responsáveis pelas estruturações lógicas de conexão (conetivos lógicos). Os "sensores" servem para perceber comparar e trabalhar cores de modo geral, além de distâncias e posições no plano cartesiano. O conjunto formado pelos "números" apresenta os operadores lógicos (maior, menor, igual, e, ou, não), as quatro operações, sorteio de números, as funções trigonométricas e suas inversas, as funções exponenciais na base 10 e suas inversas e a função modular.

O que acontece ao clicar em cada um desses grupos? Por exemplo, o grupo "movimento" é o responsável pelas estruturas de movimentação e rotação de objetos que, por ventura, serão utilizados. Como o Scratch é uma plataforma 2D, isso implica um eixo y e um eixo x, caracterizando assim, um plano cartesiano. Por tanto, ao realizar qualquer tipo de movimentação, faz-se necessário indicar as coordenadas para qual o personagem irá se movimentar, sendo o eixo $\mathrm{X}$ as movimentações horizontais, e eixo $\mathrm{Y}$ movimentações verticais. Na figura 02, o retângulo ao centro descreve as possíveis execuções de "movimento", assim como é possível identificar as coordenadas do objeto, no plano cartesiano. 
Figura 02: O movimento como exemplo de grupo de comando

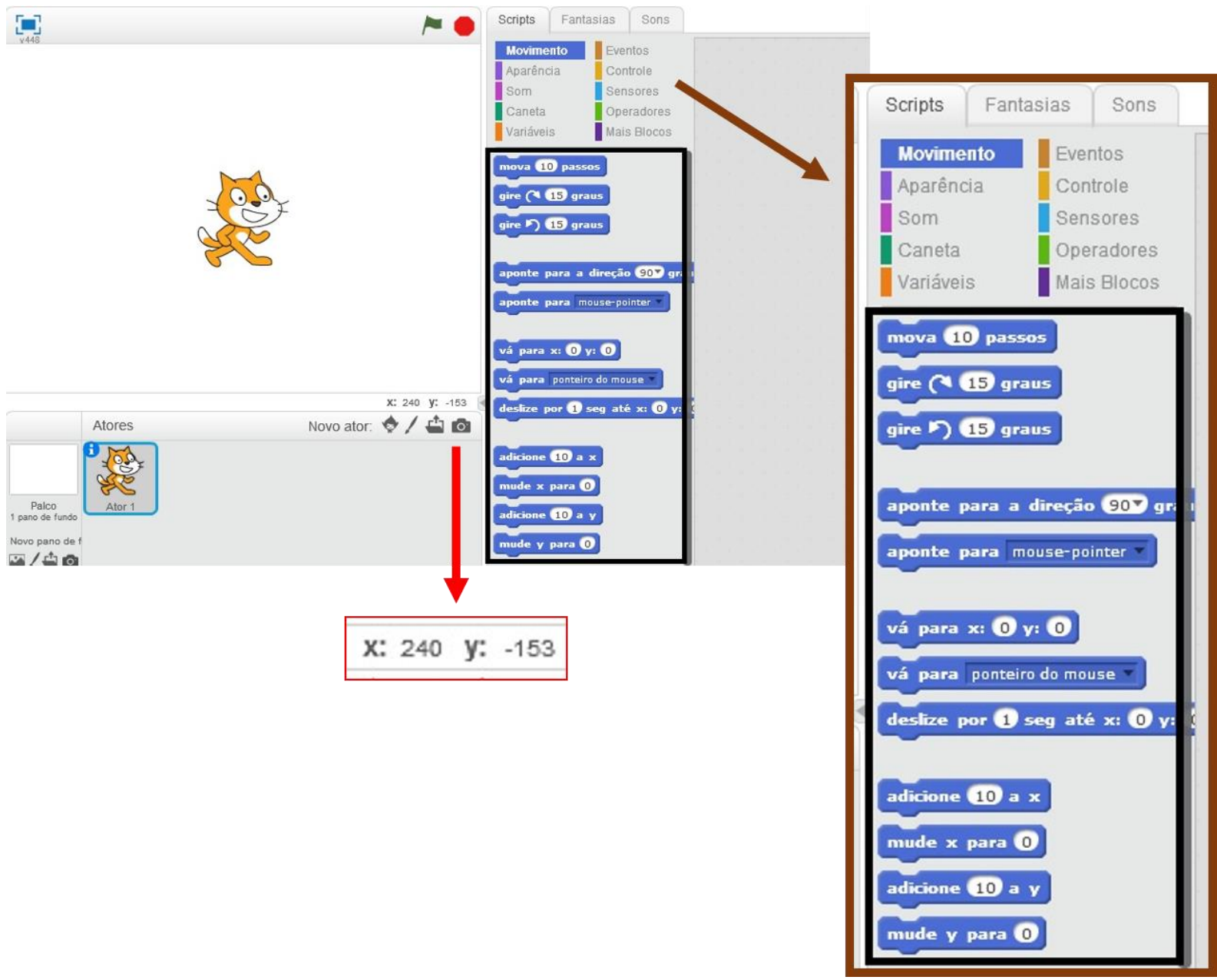

Fonte: Scrath - Adaptado pelos autores

Apesar de não ser muito robusto, esse software, possui estruturas básicas, porém importantes, para um programador como estruturas de controle de fluxo (BRESSAN, 2015). Tal ferramenta, como outras com arquitetura semelhante, buscam sanar um problema grave e recorrente no ensino de programação de alunos ingressantes em cursos de informática, pois estes geralmente demonstram muita dificuldade para a compreensão das ideias abstratas necessárias para o desenvolvimento de técnicas que possibilitam o desenvolvimento de um programa de computador. Isso porque, não é raro encontrar um aluno ingressante na área de informática, seja curso técnico, superior ou mesmo em uma pós-graduação, que desconheça completamente um sistema, uma linguagem de programação, ou um banco de dados. A disciplina de Lógica de Programação ou Algoritmos é uma das mais importantes para alunos ingressantes, pois é como um alicerce sobre a qual se edifica toda a construção das outras competências exigidas em um curso de informática (FILHO, 2016). 
Assim, a estrutura do Scratch tem auxiliado, com êxito, o aprendizado e entendimento das linguagens de programação. Segundo Santos (2014), as dificuldades percebidas no aprendizado de linguagem de programação podem ser analisadas por diversos níveis. Pois, o que se pratica hoje nas instituições, parece não dar conta de demonstrar os fundamentos necessários para o aprendizado de conceitos fundamentais, que norteiam a prática de programar. Para esse autor, o alto grau de insucesso nas disciplinas introdutórias de linguagem de programação, em qualquer nível de estudo, é tema de constante debate no meio acadêmico, pois muitas são as abordagens, porém sem nenhum resultado que possa ser considerado alvo de melhorias generalizadas. Segundo Teixeira (2015), o propósito do ensino de programação é capacitar o indivíduo a desenvolver programas computacionais com o poder de resolver problemas do cotidiano. Dessa forma, o Scratch apresenta-se como uma poderosa ferramenta para ser aplicada no ensino básico de programação, por ser muito intuitiva.

\section{Do inventário das teses e dissertações}

Esta seção se refere ao mapeamento realizado, buscando um estado da arte sobre o Scratch como auxiliar no ensino e na aprendizagem de linguagem de programação. De acordo com Messina (2012), uma pesquisa do tipo estado da arte tem a pretensão de expor o que há de mais recente sobre de terminado assunto. Busca-se, ainda, trazer ao debate elementos que permanecem na sombra, além de questões ainda não esclarecidas, bem como potencializar o desenvolvimento de uma temática, colocando-a sob um holofote. Sendo assim, uma pesquisa do estado da arte tem o potencial de ser revisado, reelaborada, redimensionada, sem nunca se fechar. Isso porque é necessário compreender que cada estado da arte faz uma leitura possível da história de certa produção acadêmica, de acordo com a proposta de cada pesquisador. Contudo e certamente, muitas outras leituras a respeito do mesmo tema são possíveis, desejáveis e indispensáveis.

Nesse sentido, o recorte proposto foi a pós-graduação brasileira, tendo como local de busca de teses e dissertações o banco de teses da CAPES. Tal repositório foi escolhido por conta de sua credibilidade, reconhecimento e qualidade de seu acervo, premissa essa, reconhecida pelos pares da comunidade acadêmica. As buscas realizadas no repositório foram feitas entre os meses outubro de 2016 a maio de 2017, por meio da

RPGE- Revista on line de Política e Gestão Educacional, Araraquara, v. 22, n. 2, p. 608-626, maio/ago., 2018. ISSN: 1519-9029. 
palavra chave Scratch, a partir da qual se obteve o resultado total de 149 Teses e Dissertações sobre o assunto.

Para canalizar temas pertinentes à proposta, filtros específicos foram utilizados, de maneira que somente os trabalhos mais relevantes e pertinentes fossem de fato inventariados para o estudo. Em um primeiro momento, foi aplicado o filtro "Grande área de conhecimento", selecionando as áreas mais aderentes ao uso do Scratch como ferramenta de ensino. O total reduziu para 73, cuja distribuição por "grande área" pode ser observada no quadro 01.

Quadro 1: Total de teses e dissertações por "grande área"

\begin{tabular}{cc|c}
\hline Grande área & Teses e dissertações & \% \\
\hline Ciências Exatas e da Terra & 25 & $18 \%$ \\
\hline Ciências Humanas & 12 & $9 \%$ \\
\hline Ciências Sociais Aplicadas & 5 & $4 \%$ \\
\hline Multidisciplinar & 30 & $22 \%$ \\
\hline TOTAL & $\mathbf{7 3}$ & $\mathbf{1 0 0 \%}$ \\
\hline
\end{tabular}

Fonte: Elaborado pelos autores

Os dados apresentados no quadro evidenciam que as grandes áreas "Multidisciplinares" e "Ciências Exatas e da Terra" são as que mais obtiveram resultados relevantes, sendo estas selecionadas, chegando ao um número total de 55 Teses e Dissertações.

Na sequência, utilizamos o conteúdo como filtro, isto é, buscou-se na leitura dos títulos e resumos, teses e dissertações que estivessem alinhadas com a proposta desta pesquisa: o Scratch como ferramenta auxiliadora no processo de ensino-aprendizagem de linguagem de programação. Depois de aplicar este filtro, chegou-se em 12 trabalhos.

Esses foram inventariados de acordo com os seguintes atributos: ano de defesa, instituição e nível, mestrado ou doutorado (quadro 02); identificação e formação dos autores (quadro 03); e metodologia aplicada na pesquisa, objetivos e público-alvo (quadro 04).

Quadro 2: Teses e Dissertações escolhidas para esse trabalho, por ano e Universidade.

\begin{tabular}{ccc|c}
\hline Universidades & Ano & Nível \\
\hline UFRGS (Universidade federal do Rio Grande do Sul) & 2010 & mestrado \\
\hline UPF (Universidade de Passo Fundo) & 2012 & mestrado \\
\hline PUC-SP (Pontifícia Universidade Católica São Paulo) & 2014 & mestrado \\
\hline
\end{tabular}




\begin{tabular}{|c|c|l|}
\hline UFSC (Universidade Federal de Santa Catarina) & 2015 & mestrado \\
\hline UNEB (Universidade do Estado da Bahia) & 2015 & mestrado \\
\hline UFSM (Universidade Federal de Santa Maria) & 2015 & mestrado \\
\hline UPF (Universidade de Passo Fundo) & 2015 & doutorado \\
\hline UCPEL (Universidade Católica de Pelotas) & 2016 & doutorado \\
\hline ULBRA (Universidade Luterana do Brasil) & 2016 & mestrado \\
\hline UNICAMP (Universidade Estadual de Campinas) & 2016 & mestrado \\
\hline UNICAMP (Universidade Estadual de Campinas) & 2016 & mestrado \\
\hline
\end{tabular}

Fonte: Elaborado pelos autores

Segundo esse inventário, verificamos que nos anos seguintes ao lançamento do Scratch a produção foi tímida, sendo que em 2015 e 2016 é possível observar um aumento e manutenção de trabalhos. Também pode-se perceber um grande interesse da área da educação em usar objetos de aprendizagens, como instrumento facilitador no processo de ensino e aprendizagem nas mais diferentes disciplinas da formação básica dos alunos.

Quadro 03: Identificação e formação dos autores

\begin{tabular}{ll}
\hline \multicolumn{1}{c}{ Autores } & \multicolumn{1}{c}{ Formação } \\
\hline Adriano Canabarro Teixeira & Doutor em Educação \\
\hline Aldo Mende Filho & Mestre em Educação \\
\hline Amilton Rodrigues de Quadro Martins & Mestre em Educação \\
\hline André Eduardo Ventorine & Mestre em Matemática \\
\hline Angelo Costa dos Santos & Mestre em Educação \\
\hline Carolina Campos Rodeghiero & Doutora em Letras \\
\hline Emerson Rodrigo Baião & Mestre em Educação \\
\hline Manuelle Lopes Bressan & Mestre em Tecnologia \\
\hline Patricia Rocha & Mestre em Processos Tecnológicos \\
\hline Paulo Santana Rocha & Mestre em Tecnologia \\
\hline Ramon dos Santos Lummetz & Mestre em Matemática \\
\hline
\end{tabular}

Fonte: Elaborado pelos autores

No quadro anterior, podemos observar a formação de cada autor inventariado e a área da qual eles pertencem. Podemos observar que foram desenvolvidas duas teses e nove dissertações, sendo a maioria em programas de pós-graduação em educação. 
Quadro 04: Autor, metodologia aplicada na pesquisa, objetivos e público-alvo

\begin{tabular}{|c|c|c|c|}
\hline Autor & Metodologia & Objetivos & Público Alvo \\
\hline $\begin{array}{c}\text { Adriano Canabarro } \\
\text { Teixeira }\end{array}$ & Oficina & $\begin{array}{c}\text { Criar oficinas de } \\
\text { desenvolvimento para } \\
\text { alunos do } 9^{\circ} \text { ano }\end{array}$ & $\begin{array}{l}\text { Alunos do Ensino } \\
\text { Fundamental II }\end{array}$ \\
\hline Aldo Mende Filho & $\begin{array}{c}\text { Revisão } \\
\text { Bibliográfica }\end{array}$ & $\begin{array}{l}\text { Fazer uma análise } \\
\text { aprofundada da ferramenta }\end{array}$ & Pesquisadores \\
\hline $\begin{array}{l}\text { Amilton Rodrigues de } \\
\text { Quadros Martins }\end{array}$ & $\begin{array}{l}\text { Análise da } \\
\text { Ferramenta }\end{array}$ & $\begin{array}{c}\text { Propostas para a aplicação } \\
\text { da ferramenta }\end{array}$ & $\begin{array}{l}\text { Alunos do Ensino } \\
\text { Fundamental I }\end{array}$ \\
\hline $\begin{array}{l}\text { André Eduardo } \\
\text { Ventorini }\end{array}$ & $\begin{array}{l}\text { Análise da } \\
\text { ferramenta }\end{array}$ & $\begin{array}{c}\text { Pensar no uso da } \\
\text { ferramenta para aplicar no } \\
\text { contexto do aprendizado } \\
\text { de Física }\end{array}$ & $\begin{array}{l}\text { Alunos do Ensino } \\
\text { Médio }\end{array}$ \\
\hline Angelo Costa dos Santos & $\begin{array}{c}\text { Revisão } \\
\text { Bibliográfica }\end{array}$ & $\begin{array}{c}\text { Analisar a proposta de três } \\
\text { pesquisadores sobre o } \\
\text { poder educacional da } \\
\text { ferramenta Scratch }\end{array}$ & Pesquisadores \\
\hline $\begin{array}{l}\text { Carolina Campos } \\
\text { Rodeghiero }\end{array}$ & Pesquisa de Campo & $\begin{array}{l}\text { Ressaltar a necessidade de } \\
\text { se desenvolver um } \\
\text { trabalho participativo, } \\
\text { inclusivo, que fomente o } \\
\text { trabalho em equipe }\end{array}$ & Pesquisadores \\
\hline Emerson Rodrigo Baião & Desenvolvimento & $\begin{array}{l}\text { Proposta do uso da } \\
\text { ferramenta para auxiliar } \\
\text { no desenvolvimento de } \\
\text { pesquisas com arduíno }\end{array}$ & $\begin{array}{l}\text { Alunos de } \\
\text { Graduação }\end{array}$ \\
\hline Manuelle Lopes Bressan & Oficina & $\begin{array}{l}\text { Verificar se o Scratch } \\
\text { pode de alguma maneira, } \\
\text { contribuir para o } \\
\text { desenvolvimento criativo } \\
\text { de crianças e adolescentes. }\end{array}$ & $\begin{array}{l}\text { Alunos do Ensino } \\
\text { Fundamental I }\end{array}$ \\
\hline Patricia Rocha & $\begin{array}{c}\text { Revisão } \\
\text { Bibliográfica }\end{array}$ & $\begin{array}{l}\text { O uso de ferramentas } \\
\text { digitais na prática de } \\
\text { letramento de alunos com } \\
\text { limitações auditiva }\end{array}$ & Professores \\
\hline Paulo Santana Rocha & Oficina & $\begin{array}{l}\text { Apresentar metodologias } \\
\text { de ensino baseadas no } \\
\text { Sistema Personalizado de } \\
\text { Ensino }\end{array}$ & $\begin{array}{l}\text { Alunos de } \\
\text { Graduação }\end{array}$ \\
\hline $\begin{array}{c}\text { Ramon dos Santos } \\
\text { Lummetz }\end{array}$ & $\begin{array}{c}\text { Revisão } \\
\text { Bibliográfica }\end{array}$ & $\begin{array}{c}\text { Desenvolvimento do } \\
\text { Pensamento } \\
\text { computacional }\end{array}$ & Pesquisadores \\
\hline
\end{tabular}

Fonte: Elaborado pelos autores

Sobre as metodologias utilizadas e os objetivos, observamos que elas se dividem em (1) Oficinas, quando o pesquisador cria um plano de aula e aplica a ferramenta com um público específico, no intuito de analisar o comportamento diante da nova solução - 
encontramos quatro trabalhos nessa linha; (2) Revisão bibliográfica, trabalho que visa fazer uma análise da ferramenta com base no levantamento de materiais encontrados, um trabalho que tem como público alvo acadêmicos que buscam embasamento teórico sobre o assunto - foram inventariados quatro produtos nessa linha; (3) Análise da ferramenta, na qual se procura fazer uma observação, análise e demonstração das principais funcionalidades, explorando, item a item, e realizando exemplos de seu funcionamento e como pode ser aplicado em diversos contextos - do material inventariado duas pesquisas se encaixam nessa linha; (4) Pesquisa de campo, na qual o pesquisador vai até um ambiente específico e implementa a ferramenta afim de observar o comportamento e recolher resultados diante da solução apresentada - apenas um dos trabalhos levantados tem essa característica; e, por fim (5) desenvolvimento, no qual o pesquisador desenvolve uma solução utilizando o Scratch para aplicar em uma disciplina em específico, por exemplo, desenvolvendo um jogo para auxiliar o ensino de física - apenas um dos trabalhos inventariados tem essa característica.

Já os públicos-alvo das pesquisas inventariadas variaram entre (1) Pesquisadores, ou seja, quando a pesquisa tem como público outros pesquisadores interessados em abordar o tema Scratch. Nesse cenário, o objetivo é, analisar o que se tem de material teórico sobre a ferramenta e expor os prós e contras a acerca do assunto - quatro produtos tiveram pesquisadores como público-alvo; (2) Alunos de diversos níveis, nesse seguimento vão variar público do ensino fundamental I e II, alunos do ensino médio e alunos de graduação, em todos os cenários a abordagem visa analisar o mesmo problema, que é a dificuldade de abstração dos conceitos básicos de lógica de programação - cinco dissertações e uma tese se enquadram neste item; e, por fim (3)

Professores, nesse público alvo temos a intenção de preparar o profissional a aplicar novas tecnologias como apoio do ensino-aprendizado, no caso do trabalho aqui inventariado, o uso do Scratch, como ferramenta de apoio e facilitador na abstração de conceitos fundamentais da linguagem de programação - aqui, apenas um trabalho foi enquadrado nesta categoria.

\section{Análise das pesquisas de pós-graduação mapeadas}

Nesta seção, apresentam-se, de forma qualitativa, as 11 teses e dissertações mapeadas, buscando apresentar o avanço das pesquisas a respeito do Scratch como 
ferramenta de ensino de lógica de programação, bem como identificar possíveis lacunas e oportunidades para novas pesquisas.

01. Desenvolvimento de uma metodologia para o uso do Scratch for arduino no Ensino Médio

Tipo: Mestrado

Ano de defesa: 2016

Autor: Emerson Rodrigo Baião, Educação

Orientador: Prof. Dr. Sérgio Ferreira do Amaral

\section{Instituição: UNICAMP}

Síntese: Este trabalho tem como foco fazer uma análise rápida do avanço das novas tecnologias nas salas de aula e propõe o uso de uma metodologia para auxiliar a prática de ensino de robótica usando Arduíno. Para isso, usa-se a ferramenta Scratch para estimular o raciocínio lógico e tornar mais prática a programação dos projetos. A ferramenta é usada na disciplina de física. Segundo o próprio autor, seu propósito foi o de encontrar um método que possibilitasse a interação da linguagem de programação Scracth for Arduino e suas shields para trabalhar de forma prática o desenvolvimento dos conhecimentos e habilidades da disciplina de Física do $3^{\circ}$ ano do Ensino Médio. Ao final, pode-se constatar que os alunos participantes da Oficina passaram a se interessar muito mais pela disciplina e passaram a se sentir mais seguros em aulas que julgavam muita herméticas.

02. Utilizando o Scratch para valorizar a autoria e a autonomia discente em projetos pedagógicos interdisciplinares nos conteúdos dos parâmetros curriculares nacionais (PCNS)

\section{Tipo: Mestrado}

Ano de defesa: 2016

Autor: Aldo Mendes Filho, Educação

Orientador: Prof. Dr. Sergio Ferreira do Amaral

\section{Instituição: UNICAMP}

Síntese: Neste trabalho, o autor procura demonstrar como a ferramenta Scratch tem potencial para auxiliar o aluno a desenvolver melhor a sua capacidade de abstração dos conteúdos interdisciplinares do Ensino Fundamental II. Buscou-se, de acordo com o próprio pesquisador, desenvolver uma análise sobre "como a linguagem visual de programação Scratch permite desenvolver atividades relacionadas aos conteúdos das disciplinas escolares dos Parâmetros Curriculares Nacionais” (FILHO, 2016, p. 10). O 
autor levantou uma série de trabalhos elaborados no mundo inteiro, chegando a um resultado que demonstrava um aumento da capacidade de entendimento do conceito de interdisciplinaridade, quando um Objeto de Aprendizagem como o Scratch é usado assertivamente.

03. Aprendizagem conectada em modos de participação no Scratch: proposta de tipologia

Tipo: doutorado

Ano de defesa: 2016

Autor: Carolina Campos Rodeghiero, Letras

Orientador: Profa. Dra. Raquel Recuero

Instituição: Universidade Católica de Pelotas

Síntese: Nesta tese, a autora ressalta a necessidade de se desenvolver um trabalho participativo, inclusivo, que fomente o trabalho em equipe. Para isso ela faz uso do Scratch. Aqui a autora chega a conclusão de que é indispensável o uso de ferramentas de apoio no processo de ensino-aprendizagem para fomentar a cooperação, condição necessária para geração de um ambiente saudável de trabalho. Foi-se identificado, portanto, que o Scratch pode ser muito útil na consolidação de um ambiente sadio de ensino-aprendizagem.

04. As Potencialidades do uso do software Scratch para a construção da Literacia Digital

\section{Tipo: Mestrado}

Ano de defesa: 2016

Instituição: Universidade Luterana do Brasil

Autor: Ramon dos Santos Lummertz, Matemática

Orientador: Prof. Dr. Rodrigo Dalla Vecchia

Síntese: O autor dessa dissertação de Mestrado em Ensino de Ciências e Matemática aborda o potencial do software de programação Scratch. O autor, por meio de revisão bibliográfica, revela o quanto a ferramenta mostrou-se útil na abstração de conteúdos que outrora eram considerados demasiadamente complexos pelos alunos. Ele anota que vários trabalhos corroboram a sua ideia inicial, que era analisar o potencial do Scratch como estrutura atrativa, que incentiva e encoraja as pessoas a confrontar determinados conteúdos, para conseguir por em prática em suas aplicações.

05. Práticas de letramento digital de alunos surdos no ambiente Scratch

Tipo: Mestrado

RPGE- Revista on line de Política e Gestão Educacional, Araraquara, v. 22, n. 2, p. 608-626, maio/ago., 2018. ISSN: 1519-9029. 
Ano de defesa: 2015

Autor: Patrícia Rocha Rodrigues, Tecnologia

Instituição: Universidade do Estado da Bahia

Orientador: Profa. Dra. Lynn Rosalina Gama Alves

Síntese: O texto inicia-se com uma breve análise da disseminação das TIC (Tecnologias da Informação e Comunicação) e o uso de ferramentas digitais na prática de letramento de alunos com limitações auditiva. Segundo a autora, o Scracth foi escolhido pelo seu visual lúdico e fácil manuseio, salientando, ainda, a possibilidade de compartilhamento de jogos desenvolvidos no site da ferramenta. A autora promoveu oficinas com alunos com idade de 10 a 12 anos. No texto, relata-se que as práticas de letramento digital utilizadas demonstraram uma atuação ativa e reflexiva. Isso foi possível graças ao uso de diferentes recursos de significação, disponíveis no ambiente Scratch, desempenhando processo de leitura visual e reconhecimento de padrões.

06. Construção de relações funcionais através do software Scratch

Tipo: Mestrado

Ano de defesa: 2015

Autor: André Eduardo Ventorini, Matemática

Orientador: Profa. Dra. Leandra Anversa Fioreze

Instituição: Universidade Federal de Santa Maria

Síntese: Esse trabalho tem como foco a área de física e o uso da ferramenta Scratch como meio facilitador no processo abstração de fórmulas e cálculos. Trata-se de uma pesquisa de mestrado envolvendo alunos do primeiro ano do Ensino Médio, que visa analisar as potencialidades do software de programação Scratch no desenvolvimento de Objetos de Aprendizagem, voltados ao ensino de funções, funções inversas e plano cartesiano. O autor escolheu o Scratch por ser um software em duas dimensões, tendo um eixo vertical Y e um eixo horizontal X. Ao final, o autor reconhece que o Scracth é capaz de permitir ao alunado formalizar e abstrair conceitos matemáticos.

07. Avaliando a Contribuição do Scratch para a Aprendizagem pela solução de problemas e o desenvolvimento do Pensamento Criativo

Tipo: Mestrado

Ano de defesa: 2015

Instituição: UFSC

Autor: Manuelle Lopes Quintas Bressan, Tecnologia

Orientador: Profa. Dra. Marília Abrahão Amaral 
Síntese: Neste trabalho, a autora tem como objetivo verificar se o Scratch pode, de alguma maneira, contribuir para o desenvolvimento criativo de crianças e adolescentes. Ela usou uma abordagem baseada em problemas, criando uma oficina de estudos no contraturno dos alunos. Como resultados, a autora consegue demonstrar dados expressivos de sua pesquisa, tais como, a melhora na leitura e da escrita, graças a capacidade da ferramenta em permitir o uso de diversos personagens, além da possibilidade de criar jogos com o enredo que o aluno desejar.

08. Programação de computadores para alunos do ensino fundamental: a Escola de Hackers

\section{Tipo: Dutorado}

Ano de defesa: 2015

\section{Instituição: UPF}

Autor: Adriano Canabarro Teixeira, Educação

Orientador: Profa. Dra Ariane Mileidi Pazinato

Síntese: $\mathrm{O}$ autor defende que a programação de computadores tem sido utilizada como instrumento pedagógico, nas instituições educacionais de Passo Fundo/RS, por meio do projeto Escola de Hackers, que começou a vincular em 2014. As atividades de ensino foram oferecidas nos laboratórios de informática de vinte e uma Escolas Municipais, sendo as turmas formadas por alunos do $6^{\circ}$ ao $9^{\circ}$ ano do Ensino Fundamental, utilizando o ambiente de programação Scratch. Como resultado, o autor observou um interesse exponencial dos alunos das escolas onde o experimento foi aplicado em entender conceitos matemáticos para poderem aplicar em seus jogos. $\mathrm{O}$ autor também explica que a intenção do projeto não é abordar a prática Hacker, mas, demonstrar que aprender linguagem de programação é essencial nos dias de hoje, inclusive para entender e aplicar boas práticas computacionais para elaborar aplicações de qualidade e saber identificar indivíduos mal-intencionados. Com isso o autor atinge resultados expressivos no que diz respeito a práticas éticas de programação.

09. Aprendizagem mediada por linguagens de autoria: O Scratch na visão de três pesquisadores

Tipo: Mestrado

Ano de defesa: 2014

Autor: Ângelo Costa dos Santos, Letras

Orientador: Prof. Dr Fernando José de Almeida

Instituição: PUC-SP

RPGE- Revista on line de Política e Gestão Educacional, Araraquara, v. 22, n. 2, p. 608-626, maio/ago., 2018. ISSN: 1519-9029. 
Síntese: A dissertação buscou analisar o potencial e as limitações do Scratch como ferramenta de apoio do processo de ensino-aprendizagem. Na pesquisa, foi realizado levantamento qualitativo do Estado da Arte, cujo os resultados obtidos foram a demonstração de uma linha crescente do uso do Scratch em cursos de Informática, que, apesar de não substituir as linguagens formais de programação, é uma alternativa muito bem aceita e funcional para o ensino de conceitos chaves de estruturas de algoritmos.

10. Usando o Scratch para potencializar o pensamento criativo em crianças do ensino fundamental

Tipo: Mestrado

Ano de defesa: 2012

Instituição: Universidade de Passo Fundo

Autor: Amilton Rodrigo de Quadros Martins, Letras

Orientador: Prof. Dr. Adriano Canabarro Teixeira

Síntese: O presente trabalho busca analisar o potencial de um ambiente de computação bem estruturado para auxiliar e aumentar a qualidade do pensamento criativo de estudantes do ensino fundamental. A intenção foi buscar subsídios para a compreensão do potencial desses ambientes, no desenvolvimento do pensamento criativo, pautado na autonomia, na curiosidade e no protagonismo. É nesse contexto que o Scratch aparece como uma solução bastante versátil e atrativa, dada sua interface visual. Observou-se, nos resultados, um aumento no interesse de se aprender não só programação, mas também matemática, história, física, geografia etc.

11. Ensino e aprendizagem de programação: análise da aplicação de proposta metodológica baseada no sistema personalizado de ensino

Tipo: Mestrado

Ano de defesa: 2010

\section{Instituição: UFRGS}

Autor: Paulo Santana Rocha, Tecnologia

Orientador: Profa. Dra. Dionne Monteiro

Síntese: Ensino e aprendizagem de linguagem de programação está no cerne de muitas pesquisas, dada a observação e relatos das dificuldades discentes no entendimento de conceitos relacionados a esse conteúdo em particular. Aqui, o autor apresenta metodologias de ensino baseadas no Sistema Personalizado de Ensino, e da integração de diversas plataformas, como AVA, Moodle e o software Scratch como instrumentos mediadores, levantando e analisando os resultados após a implantação em uma 
instituição de ensino. Seus resultados demonstram como o uso do Scratch auxiliou alunos que demonstravam grandes dificuldades em disciplinas de programação. $\mathrm{O}$ autor observa como a interface visual em blocos e dividida por cores, facilita o entendimento de programação.

$\mathrm{Na}$ análise qualitativa, observamos que há muitas iniciativas que utilizam o Scratch, e que cada vez mais a prática de inserção de novas tecnologias como ferramenta de apoio ao ensino-aprendizagem de linguagem de programação está se disseminando. No entanto, sentimos falta de conteúdos mais concretos e projetos que utilizem de fato essas ferramentas no plano de aula. Esse fato, explica Martins (2012), pode se dar pela resistência das instituições de ensino em adotar novas ferramentas no plano de aula de lógica de programação, e pela maior intimidade dos docentes com as linguagens escritas e de mercado.

Mesmo assim, é possível observar que, cada vez mais, as ferramentas visuais têm contribuído positivamente no desenvolvimento e assimilação dos conteúdos de lógica de programação. Segundo Santos (2014), há uma necessidade em se criar programas que preparem e estimulem os professores a utilizarem as novas tecnologias como ferramenta de trabalho na construção do conhecimento. A aposta é que a praticidade do uso Scratch o torna uma dessas ferramentas.

\section{Considerações finais}

Depois de apresentar o Scratch e de realizar buscas no banco de teses da CAPES, localizamos 11 produções (dissertações ou teses) que colaboram com a proposta de utilização da ferramenta como apoio no processo de ensino-aprendizagem de lógica de programação. Nestes, pudemos notar que nos primeiros anos após o lançamento da ferramenta, houve uma pequena demanda de pesquisas em volta do assunto mas, conforme os anos foram passando e a ferramenta foi se consagrando, observamos um aumento gradativo nas pesquisas focando seu potencial educativo. Ainda no que diz respeito ao inventário, observamos pesquisas realizadas pelo país inteiro, sendo que a maioria delas diz respeito ao uso do Scratch como instrumento de apoio de ensino-aprendizagem de linguagem de programação para ser aplicado nas mais diversas áreas de ensino.

Importante anotar que, desde o lançamento da versão Scratch 2.0, em 2013, o MIT, instituto responsável pela continuidade e futuro da ferramenta, não apresenta 
nenhuma notícia a respeito de inovações. Talvez porque novas plataformas tenham surgido, seguindo o mesmo conceito propagado pelo Scratch. Dentre essas, podemos citar o AppIventor, do próprio MIT, assim como as ferramentas Alice, Stencyl, Construct 2, entre outras.

Ao observar o crescente número de ferramentas que trabalham com a programação em blocos, Gonçalves (2014), apontou que esta é uma tendência que só vem aumentando, dada a fácil assimilação, compreensão e desenvolvimento que essas plataformas nos proporcionam. Dessa forma, parece que temos, como apontou Santos (2014), uma tendência se consolidando no processo de ensino-aprendizagem de linguagem de programação em todos os níveis e modalidades de ensino: a interface visual em blocos. Dessa forma, vimos que o Scratch tem cumprido sua missão e que a linguagem de programação tem se tornado cada vez mais acessível aos professores e estudantes.

\section{REFERÊNCIAS}

BAIÃO, Emerson Rodrigo. Desenvolvimento de uma Metodologia para o uso do Scratch for arduino no Ensino Médio. 2016. 150 f. Dissertação (Mestrado) - Curso de Educação, Unicamp, Campinas, 2016.

BRESSAN, Manuelle Lopes Quintas. Avaliando a contribuição do Scratch para a aprendizagem pela solução de problemas e o desenvolvimento do pensamento criativo. 2015. 526 f. - Dissertação de Mestrado - Curso de Informática, Universidade Federal de Santa Catarina, Florianópolis, 2015.

FERREIRA, Norma Sandra de Almeida. As pesquisas denominadas "estado da arte". Educação e Sociedade, Campinas, v. 23, n. 79, p. 257-272, 2002.

GONÇALVES, Felippe Albuquerque. Desenvolvimento de um novo objeto de aprendizagem para o ensino de probabilidade no ensino médio. 2014. 35f. Tese (Doutorado) - Curso de Matemática, Universidade Federal da Paraíba, Campina Grande, 2014.

LUMMERTZ, Ramon dos Santos. As Potencialidades do uso do software Scratch para a construção da literacia digital. 134 f. Dissertação (Mestrado) - Curso de Matemática, Universidade Luterana do Brasil, Canoas, 2016.

MARTINS, Amilton Rodrigo de Quadros. Usando o Scratch para potencializar o pensamento criativo em crianças do ensino fundamental. 112f. Dissertação (Mestrado) - Curso de Letras, Universidade de Passo Fundo, Passo Fundo, 2012.

MENDES FILHO, Aldo. Utilizando o Scratch para valorizar a autoria e a autonomia discente em projetos pedagógicos interdisciplinares nos conteúdos dos 
parâmetros curriculares nacionais. 153f. Dissertação (Mestrado) - Curso de Educação, Unicamp, Campinas, 2016.

MESSINA, Graciela. Investigación en o investigación acerca de la formación docente: unestado del arte en los noventa. Revista Iberoamericana de Educación, Madrid, n. 19, p. 145-207, 1999.

ROCHA, Paulo Santana. Ensino e aprendizagem de programação: análise da aplicação de proposta metodológica baseada no sistema personalizado de ensino. 95 f. Dissertação (Mestrado) - Curso de Tecnologia, UFRGS, Porto Alegre, 2010.

RODEGHIERO, Carolina Campos. Aprendizagem conectada em modos de participação no Scratch: proposta de tipologia. $140 \mathrm{f}$. Tese (Doutorado) - Curso de Letras, Universidade Católica de Pelotas, Pelotas, 2016.

RODRIGUES, Patrícia Rocha. Práticas de letramento digital de alunos surdos no ambiente Scratch. 112 f. Dissertação (Mestrado) - Curso de Tecnologia, Universidade do Estado da Bahia, Salvador, 2015.

SANTOS, Ângelo Costa dos. Aprendizagem mediada por linguagens de autoria: o Scratch na visão de três pesquisadores. 95 f. Dissertação (Mestrado) - Educação: currículo, PUC-SP, São Paulo, 2014.

TEIXEIRA, Adriano Canabarro. Programação de computadores para alunos do ensino fundamental: a Escola Hacker. 121 f. Dissertação (Mestrado) - Curso de Educação, Universidade de Passo Fundo, Passo Fundo, 2015.

VENTORINI, André Eduardo. Construção de relações funcionais através do software Scratch.. 112 f. Dissertação (Mestrado) - Curso de Matemática, Universidade Federal de Santa Maria, Santa Maria, 2015.

\section{Como referenciar este artigo}

CAMARGO, Ivan Rodrigues de; FORTUNATO, Ivan. O Scratch como auxiliar no processo de ensino-aprendizagem de linguagem de programação: um balanço da pósgraduação nacional entre 2010 e 2016. Revista on line de Política e Gestão Educacional, Araraquara, v. 22, n. 2, p. 608-626, maio/ago., 2018. ISSN: 1519-9029. DOI: 10.22633/rpge.v22.n2.maio/ago.2018.10754

Submetido em: 03/12/2017

Aprovado em: 30/04/2018 